\title{
Prospects and Challenges of Agricultural Mechanization in Oromia Regional State-Ethiopia, Policy Perspectives
}

\author{
Tamrat Gebiso Challa \\ Oromia Agricultural Research Institute, Asella Agricultural Engineering Research Center, Asella, Ethiopia
}

\section{Email address:}

tameulove@yahoo.com

To cite this article:

Tamrat Gebiso Challa. Prospects and Challenges of Agricultural Mechanization in Oromia Regional State-Ethiopia, Policy Perspectives. American Journal of Agriculture and Forestry. Vol. 4, No. 5, 2016, pp. 118-127. doi: 10.11648/j.ajaf.20160405.12

Received: August 11, 2016; Accepted: August 25, 2016; Published: September 12, 2016

\begin{abstract}
The use of agricultural mechanization technologies is equally important in boosting agricultural outputs as that of other biological technologies. To realize this number of stakeholders was involved in doing research, multiplication, importing, disseminating technologies and other activities of extension service for farmers whether it is in organized manner or not. Considerable numbers of agricultural mechanization technology types were also introduced from research centers, importers (dealers), NGOs, and government bodies. However, adoption status and associated factors were not studied so far. Therefore, this research was initiated to assess adoption status of technologies and factors that affect the use and to draw some implications for policy, research, and development practitioners for further interventions. Descriptive and inferential statistics were used to summarize qualitative data and the socio-demographic data of the households and logistic regression model was employed to assess factors that determine adoption. Generally, technology utilization status was found to be very poor and different factors like age, education of households, landholding, family size and technology access were the main contributors for the low utilization. Furthermore, low attention given by government bodies was the most critical factor for mal functionality of different actors/ stakeholders in the area.
\end{abstract}

Keywords: Agricultural Mechanization Technologies, Adoption, Logistic Regression Model, National Agricultural Mechanization Strategy, Oromia Regional State

\section{Introduction}

The level, appropriate choice and subsequent proper use of mechanized inputs into agriculture has a direct and significant effect on achievable levels of land productivity, labor productivity, the profitability of farming, the sustainability, the environmental and, on the quality of life of people engaged in agricultural businesses. Therefore, the use of these mechanization technologies is essential and they are among the major inputs in agricultural businesses [1] and [2].

[3] Reported that unless the problem of farm power is given reliable solution and addressed practically in Sub Saharan African Countries (SSA), the region is at risk of increasing poverty and hunger. Moreover, this report extended emphasizing on effect of farm mechanization that these SSA countries are unlikely unable to attain the Millennium Development Goal of halving the proportion of people suffering extreme poverty by 2015 , and the similar goal of the World Food Summit in 1996 to reduce the number of starving people by half. These and other research outputs and development practitioners' views clearly indicate the importance of agricultural mechanization technologies in increasing production and productivity and improving the livelihoods of the farmers.

There are considerable numbers of agricultural mechanization technologies that have been developed, modified and adopted by different mechanization research centers and imported by technology dealers. Most of these technologies were released by the research centers and the local multipliers are trained by those research centers to multiply the technologies. Mould bold plow, spike-tooth harrow, wheat-barley-teff thresher, maize Sheller, animal drawn carts, diffused light potato seed storage, edible potato storage and grain storage are some of the technologies that have been transferred to multipliers with their full design and production manuals [4]. On top of the formal transfer of these mechanization technologies, the private multipliers and importers (dealers) and different NGOs (like FAO who imported wheat-barley thresher and AGROW SAW seed cleaners for 
private farmers and unions from India) are also fetching different technologies which they think important and helpful for Ethiopian farmers and agriculture. Furthermore, seldom, the government of Ethiopia is also advocating the use of such technologies even though it lacks continuity, policy support and budget like the mass production and dissemination of treadle pump, BBM and modern beehives. Despite all these efforts, their utilization by end users (farmers) as elsewhere in less developed and developing countries where the importance and significance of farm mechanization is often misconstrued and meant to modernization and its utilization is overlooked [2], is too minimal.

In Ethiopia in general and specifically in Oromia region, there were rising complain at different forums from development practitioners for low utilization of the technology of agricultural mechanization and there is a need to identify the reason for the case. The research output by [5] shown that only 11percent of the sampled farmers (even though their samples were not representative as they mentioned) were reported to have used different machines. The Oromia Regional Agricultural Development Partnership Council (ADPLAC) meeting held at Adama (Nazareth) in 2011 pointed out more than thirty types of agricultural production bottlenecks of the region and the low rate of adoption or utilization of agricultural mechanization technologies was one of these mentioned critical problems. In addition to this, Asella agricultural mechanization research center as sole provider of such technologies to south-east Oromia is not facing high demand pressure from farmers for most technologies which also shows that there is low/minimal adoption. Therefore, for the ease of policy intervention by the policy makers, and development practitioners, the factors that hinder the use / adoption of those technologies must be enumerated and identified. This research proposal was also initiated to systematically study the adoption rate and factors that affect adoption of the technologies in the study area.

\section{Objectives of the Study}

Earning of productivity from agricultural mechanization requires well formulated mechanization plan of a given country which should have to be well designed, reliable and through analysis [6]. So, this should have to be done through policy intervention and there must be policy perspective research regarding agricultural mechanization determinants of the region. Therefore, the main and general objective of this research proposal was to describe mechanization status and enumerate the factors that affect the use of the agricultural mechanization technologies by smallholders from the policy perspectives of the region and the way forward for better utilization or intensification of agriculture.

\section{Research Methodology}

\subsection{Description of the Study Area, Sampling and Sample Size}

The study was conducted in Southwest Oromia regional state. The area is known by diversified agro-ecologies from lowland (East shewa which is located in Great Rift Valley) to Arsi's and Bale's highlands. The two Arsis and Bale zones of the region are known for their surplus production. The diverse landscape that causes varied microclimate of the areas helps the area to have diversified crops that is grown in these areas. Specially these areas are well known as wheat belt in the country. [7] Indicated that more than $75 \%$ of the country's bread wheat comes from these areas and [8] also mentioned that about $2 \%$ of farm production in Arsi was mechanized. The lowland parts of the area are well known for fruits production in all zones (Arsi, W/Arsi, Bale, E/Shewa). In lowland parts of Bale and E/Shewa nomadic type of animal rearing is also widely practiced.

\subsection{Sampling Procedure}

Multi-stage sampling procedure was employed. Both purposive and random sampling methods were used to select the representatives. At first stage, three zones were selected purposively based on their representativeness for the production system (majoring production type). Accordingly, Arsi, West Arsi and East Shewa zones were selected to represent wheat-barley belt areas, wheat-barley, maize and teff production areas and pulse, sorghum and maize producing areas of the region respectively. These zones are especially where there are high opportunities to be exposed to different agricultural mechanization technologies since ARDU/CADU period through different programs and mechanization research. Total of five districts (two districts each from Arsi and West Arsi zones and one district from East Shewa zone) were selected based on their accessibility, representativeness to the rest districts and their back history of access (exposure) to different agricultural mechanization technologies. At the second stage a total of ten (two PAs from each district) finally a total of valid 173 respondents were selected.

\subsection{Data Type and Methods of Data Collection}

Both primary and secondary data were collected and used in this study. To collect the data PRA approach were used. Primary data were collected by checklists, semi-structured and structured questionnaire. The type of data collected included socioeconomic and hypothesized factors to affect the use of agricultural mechanization technologies and types of agricultural mechanization technologies being used in the area. Most important data were collected through Focus Group Discussion (FGD) held with farmers and development experts. To collect data on determinants of farm technology utilization, the technologies were categorized according to their use and simplicity and the determinants were collected accordingly. Key informants of data sources were research centers, farmers and investors, extension (agriculture) bureaus, mechanization technologies multipliers, importers, primary cooperatives and unions.

\subsection{Method of Data Analysis}

Descriptive statistics like cross tabulation, mean, median, 
percentage were employed to summarize the socioeconomics characteristics of farmers and other data that were collected from other governmental and nongovernmental. In addition to the descriptive and inferential statistics, econometric model called binary logit was employed to study factors that affect adoption of agricultural mechanization technologies. The use of such determinants of groups of technologies was also practiced in [8].

Even though the statistical similarity of the outputs of logit and probit exists, [9], but logit model is easier to estimate. The objective of binary logit model was to estimate the probability of a farm household to adopt or not to adopt preharvest and/or threshing technologies. The dependent variable is dichotomous and therefore, following [10] the binary logit model is specified as follows:

$$
\ln \left\{P(X) /(1-P(X)\}=\beta_{0}+\beta_{1} \chi_{1}+\ldots+\beta_{9} \chi_{9}+\varepsilon\right.
$$

Where;

$\mathrm{X}_{\mathrm{i}}$, is the vector of independent variables representing a number of demographic and socioeconomic variables of $i^{\text {th }}$ farm household. The value of the parameters, $\beta$, measures the exponential impact of a unit change in the explanatory variables on the probability of technology adoption and $\varepsilon$ is error term.

The probability of adoption can be calculated as:

$$
\text { Adoption.prob. }=\frac{1}{1+e^{-\left(\beta_{0}+\beta_{1} \chi_{1}+\ldots .+\beta_{9} \chi_{9}+\varepsilon\right)}}
$$

\subsection{Definition of Variables in the Logistic Model}

Dependent variable: is the probability of a given $\mathrm{HH}$ to adopt one or more of pre-harvest and harvesting/ threshing technologies. For simplicity if the $\mathrm{HH}$ is found to be user of one or more of the following technologies, BBM, mould bold plows, spike-tooth harrows and tractor, combine harvester, wheat-barley-teff thresher and maize Sheller, he/she was considered as adopter.

Access to technologies: In this research, HHs' distance to main market area was taken as proxy for access to technology and expected to have negative impact.

Household age: it was hypothesized that the larger the age the lesser probability that the $\mathrm{HH}$ has to use technologies. It is expected that the younger the $\mathrm{HH}$, will have access to information.

Gender of HH head: it was expected that male headed farm $\mathrm{HH}$ will have more chance to adopt and use the technologies.

Educational background: Formal schooling enhances a farmer's ability to perceive, interpret, and respond to new events in the context of risk. Hence, education is hypothesized to increase the probability that farmers will use agricultural mechanization technologies.

Family size: it was expected that total family size affects technology adoption negatively as the more number of family size has probability of contributing more labor to farm activities.
Total land cultivated: is expected to have positive impact to adopt technology as a $\mathrm{HH}$ cultivating more land needs more labor and time-saving mechanization technologies.

Number of oxen: oxen in Ethiopia in general and in study areas specifically used as draught power and means of threshing (trampling on field called "awdima/hogdi". Therefore, the more number of oxen possessed by a $\mathrm{HH}$ the lesser the probability of using modern technologies.

Size of land owned (given from PA): this was also hypothesized to have positive impact to adopt technology similar to total land that a $\mathrm{HH}$ cultivated.

$\mathrm{HH}$ participation in community organizations/groups: for this purpose participation in seed producers group, primary cooperatives and the like was assessed and it was hypothesized that farmers' membership in these organizations have positive impact on technology adoption.

\section{Result and Discussion}

\subsection{Demographic, Socio-economic Characteristics and Resource Ownership}

Around $90 \%$ of total responds were male headed while the rest were females and when we see the marital status of responds, $90.8 \%$ of respondents were married. The mean age of the respondents was $45.25(11.07)^{* 1}$ years while it was 44.51 (10.71), and 45.86 (11.38) respectively for adopters and non-adopters. Mean family member was 7.09 (2.83) while the mean for adopters and non-adopters were 8.09 (3.21) and 6.27 (2.16) respectively. Number of family members contributing full time labor to farm activities were $2.16(0.67)$ and $2.26(0.78)$ for adopters and non-adopters respectively while the number of family members contributing partial (part-time) labor to farm activities were 3.42 (2.36) and 2.35 (1.81) for adopters and non-adopters respectively. The partial labor contributors are mostly school children who assist their families in the farm after school time and the result shows that most of the adopters are sending their children to schools and that is why they have more part-timer labor contributors and less full-timer labor contributors compared to non-adopters. The educational background of the adopters and non-adopters were 6.80 (3.50) and 4.45 (3.78) respectively which shows that education has great role in adoption of modern technologies (Table 1).

When we see resource ownership of the respondents (Table 1 and 3), the average landholding was 2.33 which is much above national average (1ha) and the smallest landholding was found in Boset (0.78ha) and Arsi Negele (1.71ha) while largest holding was in Gedeb Asasa (3.91ha). Land owned from PA, total cultivated land and rented in land were found to be higher for adopters which are 2.85, 2.79 and 0.84 ha respectively than non-adopters. The overall mean Tropical Livestock Unit (TLU) was 10.03 where it was 10.88 and 9.31 for adopters and non-adopters respectively.

1 Number in the parenthesis is standard deviation 
The largest income of the respondents comes from cereal crop production where almost $100 \%$ of adopters and around $99 \%$ of non-adopters were earning their income. The next larger income come from rearing small ruminants $(59 \%$ adopters and $62 \%$ of non-adopters) and cash crops production like potato, sugar cane, and other vegetables and it accounts for about 27 and $52 \%$ of adopters and nonadopters respectively (Table 2).

Table 1. Mean comparison of selected continuous variables for adopters and non-adopters.

\begin{tabular}{|c|c|c|c|c|}
\hline \multirow[b]{2}{*}{ Variables } & \multicolumn{4}{|c|}{ Mean values } \\
\hline & Total & Adopters & Non-adopters & t-values \\
\hline $\mathrm{HH}$ age & 45.25 & 44.52 & 45.86 & $-0.79(\mathrm{NS})$ \\
\hline HH education & 5.52 & 6.80 & 4.45 & $4.21 * * *$ \\
\hline Number of family & 7.10 & 8.10 & 6.27 & $4.44 * * *$ \\
\hline Family member contribute full labor time & 2.21 & 2.16 & 2.26 & $-0.82(\mathrm{NS})$ \\
\hline Family member contribute partial labor & 2.84 & 3.42 & 2.35 & $3.36 * * *$ \\
\hline Distance from main market areas & 87.60 & 68.24 & 103.86 & $-3.60 * * *$ \\
\hline Distance from extension service center (min.) & 47.30 & 39.02 & 54.27 & $-2.29 *$ \\
\hline Distance from credit providers & 82.20 & 69.04 & 93.27 & $-2.49 * * *$ \\
\hline Distance from local cooperative & 42.83 & 44.92 & 4278 & $0.26(\mathrm{NS})$ \\
\hline Distance from health centers & 36.61 & 33.68 & 39.06 & $-0.93(\mathrm{NS})$ \\
\hline Distance from potable water & 19.82 & 20.00 & 19.67 & 0.08 (NS) \\
\hline Land cultivated (ha) & 2.41 & 2.79 & 2.09 & $2.56 * * *$ \\
\hline Land given from $\mathrm{PA}$ & 2.33 & 2.85 & 1.90 & $3.02 * * *$ \\
\hline No. of oxen & 2.32 & 2.41 & 2.26 & $0.65(\mathrm{NS})$ \\
\hline Land under wheat production & 1.00 & 1.90 & 0.38 & $7.78 * * *$ \\
\hline Total TLU of HH & 10.03 & 10.88 & 9.31 & $1.41(\mathrm{NS})$ \\
\hline Sex: & Male & $89.60 \%$ & & \\
\hline Female & $10.40 \%$ & & & \\
\hline Marriage: & Married & $90.80 \%$ & & \\
\hline Others & $9.20 \%$ & & & \\
\hline
\end{tabular}

$* * *$ significant at $99 \%$ level, * significant at $90 \%$ level and NS=not significant

Table 2. Households' Income Sources.

\begin{tabular}{|c|c|c|c|c|c|c|}
\hline \multirow[b]{2}{*}{ Income sources } & \multicolumn{2}{|c|}{ Adopters } & \multicolumn{2}{|c|}{ non-adopters } & \multicolumn{2}{|l|}{ Total } \\
\hline & Freq & percent & frequency & percent & freq & Percent \\
\hline Cereals & 78 & 99 & 94 & 100 & 172 & 99.42 \\
\hline Cash crops & 21 & 27 & 49 & 52 & 70 & 40.46 \\
\hline Petty trade & 5 & 6 & 8 & 8.5 & 13 & 7.51 \\
\hline Small fattening & 17 & 22 & 16 & 17 & 33 & 19.08 \\
\hline Dairy & 20 & 25 & 18 & 19 & 38 & 21.97 \\
\hline Rear sheep and/goat & 47 & 59 & 6 & 6.6 & 53 & 30.64 \\
\hline Grain trading & 4 & 5 & 0 & 0 & 4 & 2.31 \\
\hline Livestock trading & 8 & 10 & 6 & 6.6 & 14 & 8.09 \\
\hline Rent house in towns & 12 & 15 & 14 & 15 & 26 & 15.03 \\
\hline
\end{tabular}

Wheat enterprise is major for Gedeb Asasa followed by Tiyo districts where each household cultivates around 2.80ha and $0.82 \mathrm{ha}$ and harvests 74.41 and 28.4 quintals of yield on average respectively. Barley is the major crop for Lemu-Bilbilo district and the second crop for Gedeb Asasa where each household cultivates 1.73ha and 0.74ha and harvests 40.19 and 16.51 quintals of grain respectively while Boset and Arsi-Negelle are majoring in maize production with average $\mathrm{HH}$ land coverage of 0.76 and 0.75 ha respectively (Table 3 ).

Table 3. Mean of Selected Demographic and Socioeconomic Variables across Districts.

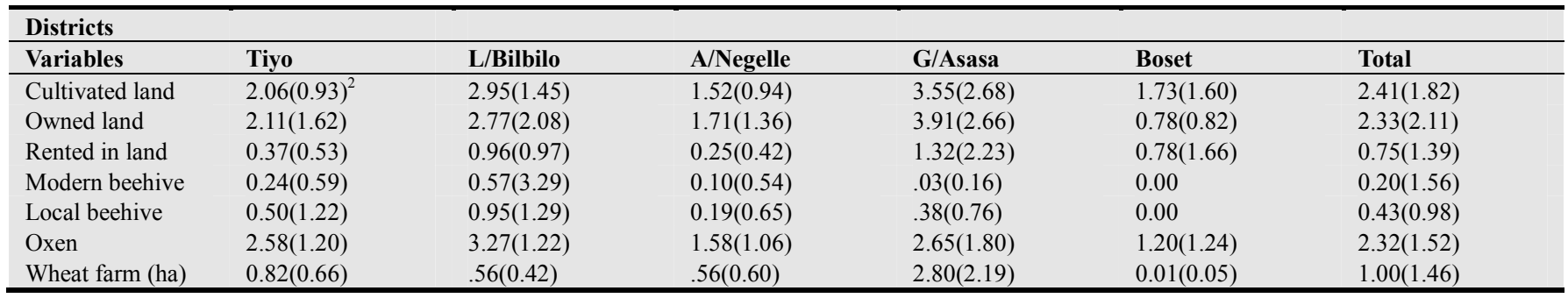

2 Numbers in brackets are standard deviations 


\begin{tabular}{|c|c|c|c|c|c|c|}
\hline \multicolumn{7}{|l|}{ Districts } \\
\hline Variables & Tiyo & L/Bilbilo & A/Negelle & G/Asasa & Boset & Total \\
\hline Wheat yield (qt) & $28.54(26.14)$ & $14.61(12.45)$ & $13.97(17.02)$ & $74.41(62.14)$ & $0.03(0.18)$ & $27.82(41.38)$ \\
\hline Barley farm & $0.44(0.52)$ & $1.73(1.09)$ & $0.10(0.16)$ & $0.74(0.88)$ & 0.00 & $0.64(0.93)$ \\
\hline Barley yield & $10.12(11.55)$ & $40.19(25.66)$ & $1.52(2.72)$ & $16.51(24.01)$ & 0.00 & $14.62(22.42)$ \\
\hline Maize farm & $0.09(0.15)$ & $0.02(0.12)$ & $0.75(0.66)$ & $0.03(0.06)$ & $0.76(0.58)$ & $0.30(0.50)$ \\
\hline Maize yield & $2.05(3.57)$ & $0.12(.46)$ & $15.47(12.46)$ & $0.68(1.93)$ & $18.58(12.22)$ & $6.61(10.78)$ \\
\hline Teff farm & $0.02(0.06)$ & $0.01(0.04)$ & $0.11(0.18)$ & $0.09(0.20)$ & $0.43(.55)$ & $0.12(0.30)$ \\
\hline Haricot bean farm & $0.11(0.65)$ & 0.00 & $0.31(0.43)$ & 0.00 & $.59(0.66)$ & $0.18(.49)$ \\
\hline Haricot bean yield & 0.00 & 0.00 & $4.02(5.15)$ & 0.00 & $8.81(15.89)$ & $2.25(7.65)$ \\
\hline TLU & $8.56(4.11)$ & $14.68(5.44)$ & $6.41(4.49)$ & $13.59(10.33)$ & $5.48(4.60)$ & $10.03(7.29)$ \\
\hline $\mathrm{HH}$ age & $45.55(10.51)$ & $48.43(10.31)$ & $42.06(12.41)$ & $46.24(10.30)$ & $43.00(11.51)$ & $45.25(11.07)$ \\
\hline Education & $6.50(3.96)$ & $5.97(3.28)$ & $6.26(3.80)$ & $6.03(3.83)$ & $2.33(2.73)$ & $5.52(3.83)$ \\
\hline No. of building & $3.24(1.05)$ & $3.86(1.13)$ & $2.61(1.26)$ & $3.27(1.48)$ & $2.20(0.76)$ & $3.09(1.29)$ \\
\hline Family size & $6.18(2.09)$ & $7.05(1.96)$ & $7.32(2.47)$ & $9.40(3.61)$ & $5.23(1.81)$ & $7.10(2.83)$ \\
\hline
\end{tabular}

\subsection{Access to Agricultural Service Providing Centers}

To estimate Agricultural mechanization technologies supply center accessibility, main market and extension service centers distance from households' home in walking minutes was taken as a proxy since these are the main places to get information and physical technologies.

Accordingly, agricultural mechanization technology users were found to be more accessible to almost all service providing center and have likely more access to agricultural mechanization technologies. For example, the mean walking time to main market place and credit providing centers were 68.24 and 69.04 minutes for adopters and 103.86 and 93.27 minutes for non-adopters respectively (Table 1).

\subsection{Agricultural Mechanization Technologies Utilization Status}

From survey result, $45.86 \%$ of the respondents were using at least one or more of agricultural mechanization technologies of pre-harvest (BBM, ARDU mould bold, spike tooth harrow, and tractor), and harvest technologies (maize-
Sheller, wheat-teff thresher and combine harvester) while the rest were completely non-users of either of above technologies. For simplicity we divided the technologies into three major categories and tried to see their utilization status.

From the survey it revealed that 36 respondents out of 173 (which are around $21 \%$ ) were using tractor in addition to other local and intermediate plows. The survey result also revealed that only 46 respondents $(26 \%)$ of the respondents were using either tractor or other intermediate technologies like BBM, ARDU mould bold plows, and or spike tooth harrows while the rest $128(74 \%)$ of the respondents were purely using local/traditional plows (Table 4).

The result further revealed that pre-harvest technology utilization was greatly varying across districts. Boset and Arsi-Negelle were found to be the least technology users (all of the respondents were non-users) followed by Tiyo and Lemu-Bilbilo districts where $81.6 \%$ and $75.7 \%$ of total respondents were non-users respectively. The highest preharvest technology users were found in Gedeb-Asasa district where $78.4 \%$ of the total respondents were technologies users (Table 4).

Table 4. Pre-harvest technologies utilization status of the respondents.

\begin{tabular}{|c|c|c|c|c|}
\hline \multirow[t]{2}{*}{ District } & \multicolumn{2}{|c|}{ Users of only local plows } & \multicolumn{2}{|c|}{ Total respondents of district } \\
\hline & Frequency & percent of district & Frequency & percent of total \\
\hline Tiyo & 31 & 81.6 & 38 & 22 \\
\hline L/Bilbilo & 28 & 75.7 & 37 & 21.4 \\
\hline Arsi Negelle & 31 & 100 & 31 & 17.9 \\
\hline Gedeb Asasa & 8 & 21.6 & 37 & 21.4 \\
\hline Boset & 30 & 100 & 30 & 17.3 \\
\hline
\end{tabular}

The common harvesting agricultural mechanization technologies used in the study areas were combine harvester and engine-driven thresher for wheat, barley and teff producing areas and maize-sheller for maize growing areas. The use of engine-driven stationary thresher was common in Arsi Negelle district for teff and wheat threshing while the rest were using combine harvesting. The use of harvesting/threshing technologies varies across districts significantly. Around $41 \%$ of total respondents were using one or more of abovementioned technologies. The least technology user was in Boset where none of the respondents use and the highest number of users was from Gedeb Asasa followed by Arsi Negelle and Tiyo districts where around $97 \%, 71 \%$, and $26 \%$ of the respondent were using one or more of mentioned harvesting/threshing technologies respectively. The ANOVA Table also shows that there were high variation of technology utilization among districts (Table 5) where chi-square is significant at $\mathrm{p}=0.000$ level. 
Table 5. Harvesting/threshing technologies utilization across districts***.

\begin{tabular}{lllllll}
\hline & \multicolumn{2}{l}{ Adoption status for harvesting/threshing technologies } & & total & \\
\hline District & Adopter & \%of adopter & non-adopter & \%of non-adopter & F & Percent \\
\hline Tiyo & 12 & 15.19 & 26 & 27.66 & 38 & 21.96 \\
L/Bilbilo & 9 & 11.39 & 28 & 29.79 & 37 & 21.39 \\
ANegelle & 22 & 27.85 & 9 & 9.57 & 31 & 17.92 \\
G/Asasa & 36 & 45.57 & 1 & 1.06 & 37 & 21.39 \\
Boset & 0 & 0 & 30 & 31.91 & 30 & 17.34 \\
Total & 79 & 100 & 94 & 100 & 173 & 100 \\
\hline
\end{tabular}

*** Chi-square value is 100.739 and significant at $1 \%$ with Likelihood ratio of 123.073

The use status of harvesting/threshing technologies was greatly influenced by $\mathrm{HH}$ head educational background, family size, distance from main market (access to technology), distance to extension service providing center and total cultivated land. Most of these technologies utilize were those producing wheat at large. From FGD it was understood that in parts of Tiyo and Lemu-Bilbilo districts, topography and soil type were the most determinants for the use of combine harvester. These districts are partly full of ups and downs which are inappropriate for currently available combine harvester models in the areas, and they have also large proportion of vertisol (black soil) where they are required to use BBM. In this case, the owners and the operators are not willing to harvest such fields for the safety of their machine.

As it is mentioned in World Bank country report 4, Arsi and some parts of Shoa were known for use of sledges to transport their produces before the introduction of intermediate and/ or modern animal drawn carts. From the survey result most of Gedeb Asasa, Arsi Negelle and Boset respondents were using metal wheel type donkey carts and tire wheel cart drawn by horse primarily meant for human transportation in urban and peri-urban areas. Most of the highland part of Arsi (Lemu-Bilbilo and part of Tiyo districts) respondents were still using sledge and back of pack animals and the main reason was that there is no rural road access and even though there is good road accessibility in some parts they are still using those traditional technologies which may be because of tradition they are accustomed to and it needs awareness creation and demonstration of such rural transport technology.

Storage problem is one of the serious problems in Ethiopia in general where majority of post harvest loss arises. According to literatures, grain damage in peasant households may be caused from two main reasons which are attacks from weevils and rodents, and moisture or growth of molds and both of the causes are due to unconditioned storage system. [11] Reported that post harvest losses for staples in Ethiopia ranges from $10-50 \%$ which is very high in a country where large number of population is suffering from food insecurity. For instance the post harvest losses storing maize grain for the period of 2-12 months in a country ranges from $11-100 \%$ which is very ironing [12]. The result of this research also show that most peasant households do not store root crops like beetroots, carrot, and potato which produced widely in highlands of Arsi Lemu-Bilbilo and Tiyo due to lack of storage or processing facilities. These root crops damage was also associated with harvesting mechanism where mostly done by digging by hoe or traditional maresha and it is injured during that period and become susceptible to spoilage by bacteria and others. In general poor storage facilities and harvest mechanisms contributes much losses to Ethiopian grain produced. For example, $69.54 \%$ of the respondents store their crops simply in polyethylene sack and put in their own living or part of house constructed for their animals and $28.30 \%$ store in a traditional unprotected and unsafe storage called "gotera" (Table 6).

Table 6. Need Assessment for the AMT use on credit basis.

\begin{tabular}{lll}
\hline Need of credit for technology & Frequency & Percent \\
\hline Interested to use on credit basis & 141 & 81.5 \\
Not interested to use on credit basis & 32 & 18.5 \\
Reasons for disinterest in credit & 5 & \\
Limited/uneconomical landholding & 5 & 15.63 \\
Need cash basis & 12 & 37.50 \\
No interest at all & 6 & 18.75 \\
Have no idea about AMT benefit & 3 & 9.38 \\
Fear of risk to payback the loan & 3 & 9.38 \\
Need to rent not to buy & 2 & 6.25 \\
Topography is not suitable & 1 & 3.13 \\
\hline
\end{tabular}

\subsection{Need Assessment for Agricultural Mechanization Technologies}

The respondents were assessed against their need for owning AMT through credit basis if it is available (Table 7). As the result demonstrates, majority of the farmers (HHs) around $81.5 \%$ of total respondents were interested in credit based provision of the intermediate improved agricultural mechanization technologies. The reason for majority of farmers not to be interested in credit based purchase was to purchase the technology on cash basis. Out of 32 not credit interested respondents, $37.5 \%$ and $15.63 \%$ were those who are interested and can afford to pay in cash basis and having limited farmland respectively. There are farmers who are already using only tractor and combine harvester by renting from investors around urban and peri-urban areas of Asasa and Asala. 
Table 7. Awareness and source of Information on agricultural mechanization technologies.

\begin{tabular}{lll}
\hline Sources of information & Frequency & Percent \\
\hline Medias & 21 & 24.14 \\
Development Agents (DA) & 42 & 48.28 \\
Neighbors & 13 & 12.94 \\
Research centers & 14 & 16.09 \\
Others like NGOs... & 12 & 13.79 \\
$\begin{array}{l}\text { Awareness status on: } \\
\text { Were aware of presence of researches and }\end{array}$ & 87 & \\
$\begin{array}{l}\text { technology multipliers } \\
\begin{array}{l}\text { Unaware of presence of research center and } \\
\text { technology multipliers }\end{array}\end{array}$ & 86 & 50.3 \\
\hline
\end{tabular}

Type of technologies they are interested in were also tried to be assessed and almost all type of technologies from land preparation, irrigation pump and seed processing. To see specifically, majority of respondents from Lemu-Bilbilo district and part of Tiyo were interested in small tractors, wheat-barley and potato harvesting and wheat-barley threshers while those from Gedeb-Asasa was interested in animal drawn harrow, tractors and combine harvesters. Farmers around Arsi Nagelle and Boset were interested in engine-driven threshers for teff harvesting and maize shellers. Majority of respondents shown their interest in using thresher (around 46.24\%), row planter (around $45.66 \%$ ), mould bold plows (around 44.51\%) and spike-tooth harrows (around 19.08\%). A considerable number of respondents also have interest to use animal drawn cart, harvesters, tractors, modern beehives, combine harvesters, cultivators and weeder. Therefore, systematic approach has to be followed by extension service providers to give tailor based extension services and to identify specific technology for specific areas.

The respondents were also asked if they know about the presence of such technology suppliers, research centers and other bodies and about half of the respondent $(49.7 \%)$ have no awareness about suppliers and research centers on agricultural mechanization technologies. The main information sources for farmers were DAs, mass media, research centers, other NGOs, and neighbors. Lack of awareness on presence and advantages of agricultural mechanization technologies was the second most important constraints for agricultural mechanization technologies utilization where $94.2 \%$ of respondents responded the case as main factor (Table 8).

Table 8. Grain Storage Facilities of the Households.

\begin{tabular}{ll|l}
\hline Storage type & Frequency & Percent \\
\hline Store in a living/animal house with a sack & 103 & 59.54 \\
Store in warehouse with a sack & 19 & 11 \\
Use modern storage "gotera" & 2 & 1.20 \\
Store in traditional storage "gotera" & 49 & 28.30 \\
\hline
\end{tabular}

\subsection{Factors Influencing Adoption of Agricultural Mechanization Technologies}

From the result of FGD held with farmers, group of district experts, zonal, regional and federal key informants and private technology multipliers, and importers accessibility to technology, awareness on the presence and advantage of technology, lack of liaising bodies among technology sources, users and other stakeholders, lack of appropriate technologies to different situations like topography, and different soil types and last but most important of all focus from policy makers to agricultural mechanization technologies were mentioned as the most determinant factors for adoption/use of the technologies.

From the result of descriptive, and inferential statistics of structured questionnaires, we can observe that amount of cultivated land and land given (owned) from PA per a household significantly affect technology use status of the household where the averages holding by adopters were 2.79 and 2.85 ha and averages of non-adopters were 2.09 and 1.90 ha (both significant at $\mathrm{p}<0.001$ ). This may partly assure the view that introduction of mechanization technologies can improve landholding per household. Regarding this, we can see also that land holding (owned from PA and total cultivated land) per HH was quite highest (3.91 and 3.55ha respectively) in Gedeb Asasa district where about $97 \%$ of the respondents were technology adopters. This research output is similar with that of [13] which was done in Gedeb Asasa and Eteya and revealed that farmers who were using combine harvester hold more land than those of using manual/conventional threshing methods. One can also assume from this research that agricultural mechanization adoption can lead to specialization of enterprises as the case in Gedeb Asasa where $78.87 \%$ of total cultivated land was covered by wheat which is in lining with principle and advantage of specialization. Both users and non-users were asked to rank the main constraints for agricultural mechanization technologies in their areas and $94.2 \%$ of adopters and $82.35 \%$ of non-adopters selected lack of awareness on advantages and presence of appropriate technologies as the main bottlenecks while $91.3 \%$ of adopters and $84.31 \%$ of non-adopters were referring lack of appropriate technologies as the main constraints for adopt (Table 3 and 9).

The other factor greatly influenced HHs technology use was household education level (t-value significant at 0.001). Large proportion of literate farmers (greater years of schooling) were using either pre-harvest technologies or harvesting/threshing technologies or both. Family size and number of family members contributing partial labor to farm activities were also factors that affect technology adoption positively while distance of household (in walking hrs) from nearby market, main market, and credit providing centers, were affecting technology adoption negatively.

Table 9. Parameter estimates of a logistic model for factors affecting farmers' adoption of agricultural mechanization technologies.

\begin{tabular}{llll}
\hline \multicolumn{4}{l}{ Parameter estimates for agricultural } \\
\hline \multicolumn{4}{c}{ mechanization adoption } \\
\hline Explanatory variables & $\boldsymbol{\beta}$ & Wald-statistics & $\operatorname{Exp~}(\boldsymbol{\beta})$ \\
\hline Age of farmer & -0.051 & $4.410^{* *}$ & 0.950 \\
Gender of farmer & -0.934 & 1.850 & 0.393 \\
Education of farmer & 0.208 & $12.571^{* * *}$ & 1.231 \\
Family size of HH & 0.341 & $12.515^{* * *}$ & 1.406 \\
\hline
\end{tabular}




\begin{tabular}{llll}
\hline \multicolumn{4}{l}{ Parameter estimates for agricultural } \\
\hline \multicolumn{4}{c}{ mechanization adoption } \\
\hline Explanatory variables & $\boldsymbol{\beta}$ & Wald-statistics & Exp $(\boldsymbol{\beta})$ \\
\hline Accessibility to technology & 0.009 & $8.300^{* *}$ & 0.991 \\
Land cultivated (ha) & 0.121 & 0.528 & 1.129 \\
No. of oxen possessed & -0.330 & $3.700^{*}$ & 0.719 \\
Land owned from PA & 0.366 & $6.888^{* * *}$ & 1.470 \\
Status of participation in & -0.226 & 0.917 & 1.443 \\
community & -0.426 & 1.661 & 0.797 \\
No. of full labor contributed by HH & 0.140 & 0.014 & 0.869 \\
Constant & & &
\end{tabular}

$*, * *, * * *$ significant 10,5 and $1 \%$ level of significance.

Model chi-square $=62.55$

Overall model R-square $=61.1 \%$; (percent of dependents explained by explanatory variables)

Sample size $=173$

-2Loglikelihood $=175.97$

Result of logistic regression (Table 9) shows that most of the variations in dependent variable (about 61\%) were cached/ explained by hypothesized variables. Out of ten explanatory variables six were statistically significant. Household head age and proxy of technology access (HHs' distance from main market) as expected had negative impacts on technology adoption ( $\mathrm{p}<0.05$ for both variables) with factor of 0.95 and 0.991 while family size, landholding given from PA and educational background of $\mathrm{HH}$ head had positive impact on technology adoption $(\mathrm{p}<0.000, \mathrm{p}<0.001$ and $\mathrm{p}<0.000$ respectively) with exponential factor of 1.406 , 1.443 and 1.231 respectively. But community participation has unexpected sign with hypothesis put by the researcher. This may be because of most of technology adopters are proactive and their needs are beyond the supply of those organizations and they dropout of them through time.

\subsection{Problems Identified and Need Policy Intervention}

a. The result revealed that training, awareness creation and supply/availability of the technology were almost nil. More than $5686 \%$ of the respondents answered that they do not know the presence of agricultural mechanization research/producing organization (Table 10). Therefore, awareness creation on available technologies, producers, importers and about the importance and advantages of modern and intermediate agricultural mechanization technologies is a crucial action to be taken by concerned bodies.

b. There is no formal procedure to recommend agricultural mechanization technologies like other agricultural technologies. In agricultural technology utilization process of the country there is formal procedure of technology release. But it is learned that, in agricultural mechanization technologies there is no such system; technologies are being recommended and released by the researcher or any other body and this has a number of negative impacts/problems on the technology transfer and generation processes. Firstly there is no participation of stakeholders in technology release process, and the technology will not reach to the intended end users. In other side there is high chance of releasing / recommending inappropriate and unfinished / unproved technologies.

c. Less emphasis from policy makers: this can be expressed by different supports which should have been provided by government specially the extension wing of the system such as structural problem in ministry of agriculture at federal level and Bureau of agriculture at regional level where there is no person concerned with the extension service provision of agricultural mechanization technologies and no credit facility for agricultural mechanization technologies either for purchase purpose or for renting which considered the nature of such technologies (its capital intensiveness).

Table 10. Reasons for not using improved intermediate and/ or modern $A M T$

\begin{tabular}{lll}
\hline Reasons for not using & Percent & Chi-square \\
\hline Do not know presence of such technologies & 56.86 & 0.131 \\
Ignorant to advantage of such technologies & 9.8 & $4.399^{*}$ \\
Small farm size & 15.69 & 0.024 \\
Limited resource & 49.02 & 2.517 \\
Lack of awareness and information & 82.35 & $18.699^{* * *}$ \\
Lack of appropriate technologies & 84.31 & $4.495^{*}$ \\
\hline
\end{tabular}

$*$, *** significant at $5 \%$ and $1 \%$ level of significance

\subsection{Linkage Among Stakeholders in Agricultural Mechanization Technologies}

For the proper and smooth working of a given system, the functionality of each actor in the system is very important. The main stakeholders in agricultural mechanization are research centers, bureau of agricultural development, technology end users (either small-scale farmers or investors) and technology producers and importers. For this research purpose producers and/ technology importers from Asella, Adama (Nazareth), Bushoftu (Debre-zeith) and Addis Ababa were selected and interviewed using checklist.

From discussion with stakeholders (especially multipliers), the relation they have is stronger with research centers where they are getting training and technology prototypes with their designs and production manuals. In this regard the sources of almost all of the technologies they are currently multiplying are research centers.

The main role player for linkage of these stakeholders would have been government body/ or simply bureau of agriculture and livestock agency as that of other technologies (agricultural inputs). But as it is already mentioned, there is no authorized and/ or responsible body from ministry/bureau of agriculture development/livestock agency, there are no binding rules and regulations to enforce the linkage and it is based on the will of individuals from the actors. From discussion with ministry and bureau of Oromia agriculture and technology multipliers, there is no formal linkage among these bodies and it dependents on individuals' interest.

\subsection{Prospects and Challenges in Agricultural Mechanization}

From the response of the respondents it can be understood that almost all respondents have an interest to use agricultural mechanization technologies and there are also many 
technology producers, importers and researcher centers which avail these technologies with all their technical backups. The producers are found in towns and cities and they can start production with simple production training and on-job supervision from research centers and other experts.

The above mentioned actors have also great interest in working on such areas and from the discussion held with some of them, there are some producers which only deal with this business along their other businesses only because of the interest they have even though it is not profitable because of different reasons mentioned above. This can be the greatest prospect/opportunity for mechanization of Oromia/Ethiopian agriculture. The recent awareness that initiated government of Ethiopia, especially on row planting could be considered as good opportunity to be used by practitioners on these areas to pass the momentum to other agricultural mechanization technologies.

The challenges may be the current land fragmentation, topography of most part of the region and the ever increasing of farm households in rural areas. In this regard land fragmentation was and also will be a challenge in future for heavy duty machineries like tractor and combine harvesters. But the seriousness of problem can be reduced by introducing intermediate technologies like small and medium size tractors and animal drawn improved implements, threshers, chain-type combine harvesters and maize shellers. Problem of topography can also be minimized by researching and introduction of appropriate technologies.

\section{Conclusion and Recommendation}

\subsection{Conclusion}

Agricultural mechanization technology use/adoption status of the respondents was found much poor and it also varies across districts which may be due to topography, landholding size, awareness difference and so on. Only $36(21 \%)$ of the respondents were one or more of pre-harvest technologies (tractor, BBM, mould bold plows and spike-tooth harrows) users while $74 \%$ of the respondents were non-users of neither of those technologies (combine harvester, thresher, and maize Sheller). There are also some missing packages for some technologies like thresher where farmers need technology to harvest before threshing. This is critical specially when there is untimely raining during harvest period. Therefore, farmers need harvester with threshing technologies and the research has to be done on this issue at least to adopt from somewhere or to modify and adapt in to existing situation of the region. Landholding, accessibility to the technology centers, educational background were main determinant factors for technology use. From discussion held with technology multipliers, extension services providers from ministry of agriculture to down district level; it was understood that the attention given to the issue of mechanization was almost null. There are so many indicators for this above ideas for example, there is no formal procedure to release (recommend) agricultural mechanization technologies as like that of crop or livestock technologies, no physical plan and/or financial budget for the activity, no strategic plan for mechanizing the country's agriculture and so on. Though there are considerable challenges for adoption of agricultural mechanization technologies, there are also more opportunities to overcome the challenges and assure the use of those technologies.

\subsection{Recommendations}

a. Development of National Agricultural Mechanization Strategy (NAMS): the country doesn't have national strategy for agricultural mechanization as a whole. Therefore, development of research based NAMS is crucial tool to move Ethiopian agriculture one step forward.

b. Establishment of Research based Agricultural Mechanization Service center: the main objectives of this service centers should be providing technical support and physically availing machines. These service centers should be established at different locations based on agro ecologies of the country and could be started at one point and expanded to other areas. The activities could be multiplying agricultural mechanization technologies which were recommended and released by research centers, providing training for experts like DAs, district SMS and farmers, providing machineries custom service rent to farmers and investors especially for capital intensive machineries like threshers, tractors and combine harvesters and providing maintenance services to machinery users are some of the services that has to be availed by agricultural mechanization service centers.

c. Re-structuring agricultural development offices from Ministry of agriculture to PA level development agents. Currently agricultural mechanization is a forgotten business in the structure of agricultural development bureaus. There is no at least a single focal person (expertise) in the system. Therefore, it is a vital action to establish a core process (team) comprising of necessary professionals which is mainly focusing on such agricultural mechanization technologies extension process.

d. Developing Strong Agricultural Mechanization Technologies Extension System which is supported by reasonable budget. There is no physical and/or financial budget for agricultural mechanization technologies extension system so far.

e. Economizing farm size per farming household: as it was it was discussed above, landholding was the most determinant factors for technology. Improving landholding is a good mechanism to increase the production scale of farm machineries and HH's welfare. But currently the average farm landholding in Ethiopia is decreasing because of increasing population and it is much lower than 2 ha [national average was below 1 ha [14]. The research output is similar to [15] which show that about $30 \%$ of Oromia region's highlands' farmers were holding less than $0.5 \mathrm{ha}$. The minimum economical landholding for DAP is 5 ha and for that of tractor is 50ha. But in Ethiopia in general and specifically in the study area the landholding is much below 
this recommended size. According to this research output, the number of landholders is increasing through time and per capita holding is decreasing. The mean holding for the sample was also 2.33ha. Therefore, to promote mechanization, facilitating way to have more size of farmland is crucial. Along with this land fragmentation is also one of the most critical problems in farm mechanization. The previous tenure system doesn't take into account the land fragmentation problem and the only thing considered was to balance the land fertility. In most part of region there was land grading based on fertility and the tenure system tried to allocate all types of land to each farmhouse hold. This created serious problem of land fragmentation which is similar with result of [16]. The average number of plots per household in study area was 4.58(3.89) plots/households. Therefore there is a need to reconsider the tenure system or another way of economizing farm mechanization technique, like pooling the adjacent farmland plots owned by different.

\section{References}

[1] J. O. Olaoye and A. O. Rotimi. "Measurement of Agricultural Mechanization Index and Analysis of Agricultural Productivity of some Farm Settlements in South West, Nigeria". Agricultural Engineering International: the CIGRE journal. Manuscript 1372. Vol XII, January 2010.

[2] FFTC Annual Report, 2005: International Workshop on Small Farm Mechanization Systems Development, Adoption and Utilization Held at the Oasis Hotel, Los Baños, Laguna, Philippines on June 13-17. "Improving small-farm productivity through appropriate machineries".

[3] Food and Agriculture Organization of the United Nations (FAO) Rome, 2006. Farm power and mechanization for small farms in sub-Saharan Africa.

[4] Gebiso T., Boka E., and Fufa D., 2014. Pre-Scaling up of OARI-Asella model-3 Multi Crop Thresher: Lesson learnt from the activity (in pipeline to be published on International Journal of Engineering Research-online).

[5] Guush B., Kalle H. and Bart M., 2016. Agricultural Mechanization in Ethiopia: Evidence from the 2015 Feed the Future survey (Ethiopian Strategy Support Program).
[6] Nwoko, S. G., 1990. Agricultural Mechanization at a Cross Road-in Nigeria. Journal of Agricultural Mechanization in Asia, Africa, and Latin America, A M A 21(3): 78-82.

[7] Hailu Gebremariam, 1992. Availability and Use of Seed in Ethiopia. Addis Ababa: Program Support Unit, Canadian International Development Agency (CIDA).

[8] Ethio-Italian Cooperation Arsi-Bale Development Project, 2002. The Atlas of Arsi.

[9] Aldrich, J. H. and Nelson, F. D., 1984. Linear Probability, Logit and Probit Model: Quantitative Application in the Social Science-Sera Miller McCun. Sage pub. Inc, University of Minnesota and Iola, London.

[10] Gujarati, D. N., 2004. Basic Economics. $4^{\text {th }}$ Edition, McGrawHill, Inc., New York.

[11] Alliance for a Green Revolution in Africa (AGRA), 2013. Establishing the status of post-harvest losses and storage for major staple crops in eleven African countries (Phase I). AGRA: Nairobi, Kenya

[12] Tadesse, A., Eticha, F., Adler, C., \& Schoeller, M., 2000. Insect pests of farm-stored maize and their management practices in Ethiopia. IOBC WPRS BULLETIN, 23(10), 4758.

[13] Hassena, M., Regassa Ensermu, W. Mwangi, and H. Verkuijl., 2000. A Comparative Assessment of Combine Harvesting Vis$\grave{a}$-vis Conventional Harvesting and Threshing in Arsi Region, Ethiopia. Mexico, D. F.: International Maize and Wheat Improvement Center (CIMMYT) and Ethiopia Agricultural Research Organization (EARO).

[14] Abera Deresa, 2009. Achievements and challenges in Ethiopian Agriculture. In ILRI (International Livestock Research Institute). 2011. Dialogue on Ethiopian agricultural development held at United Nations Conference Centre, Addis Ababa, Ethiopia, 12 November 2009. Nairobi, Kenya, ILRI.

[15] Derek H., Mekdim D., Jacob R., Anna J., and Alemayehu S., 2013. Land Constraints and Agricultural Intensification in Ethiopia: A Village-Level Analysis of High-Potential Areas.

[16] Challa, T. G. (2014). Tractor Service Price Determinants among Smallholder Farmers in Ethiopia. Open Science Repository Agriculture, Online (open-access), e45011808. doi: 10.7392/openaccess. 45011808 . 